\title{
Pituitary Apoplexy: A MRI Finding Case and Literature Review
}

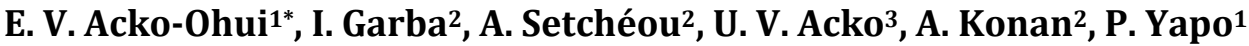 \\ ${ }^{1}$ Department of Radiodiagnosis and Medical Imaging, University Hospital (UH) of Treichville, Abidjan, Côte d'Ivoire \\ ${ }^{2}$ Department of Radiodiagnosis and Medical Imaging, University Hospital (UH) of Yopougon, Abidjan, Côte d'Ivoire \\ ${ }^{3}$ Department of Internal Medicine and Geriatrics, University Hospital (UH) of Treichville, Abidjan, Côte d'Ivoire \\ Email: *ohuiestelle@yahoo.fr
}

How to cite this paper: Acko-Ohui, E.V., Garba, I., Setchéou, A., Acko, U.V., Konan, A. and Yapo, P. (2018) Pituitary Apoplexy: A MRI Finding Case and Literature Review. Open Journal of Radiology, 8, 13-21. https://doi.org/10.4236/ojrad.2018.81002

Received: July 1, 2017

Accepted: March 2, 2018

Published: March 5, 2018

Copyright (c) 2018 by authors and Scientific Research Publishing Inc. This work is licensed under the Creative Commons Attribution International License (CC BY 4.0).

http://creativecommons.org/licenses/by/4.0/

\section{(c) (i) Open Access}

\begin{abstract}
Introduction: Pituitary apoplexy is an ischemic or hemorrhagic rearrangement within a pituitary adenoma. Pituitary apoplexy is a rare disease that constitutes a diagnosis and therapeutic emergency. Most of the time, apoplexy is the manifestation inaugural of an adenoma unknown, but it can also complicate a known adenoma. All adenomas can be concerned with the occurrence of apoplexy, with an equivalent risk, whether they are secreting or not and whatever the type of secretion. We report the case of a patient in whom the cranio-encephalic MRI enabled to make the diagnosis. Observation: A 57-years-old woman abruptly presented severe cephalodynia, followed by a left visual field defect. The clinical examination revealed an alteration of the consciousness to the type of obstruction and a decrease in left visual acuity is $4 / 10^{\text {th }}$. The cranio-encephalic MRI performed revealed an expansive intrasellar process with suprasellar extension of heterogeneous signal on all the sequences performed alternating hemorrhagic stigmata in the central tumor zone suggesting a macroadenoma having bled, compatible with pituitary apoplexy. She received medical treatment and hormonotherapy, followed by surgical excision. The outcome was satisfactory. Conclusion: Pituitary apoplexy is a rare but serious complication of pituitary adenomas. It is responsible for various neuro-ophthalmologic. Pituitary apoplexy involves the patient's functional and vital prognosis due to acute panhypopituitarism. It is a diagnostic and therapeutic emergency. MRI is a major contribution to diagnosis. Treatment is based on the combination of hormone replacement therapy and trans-sphenoidal tumor excision.
\end{abstract}

\section{Keywords}

Hypophysis, Cerebrovascular Apoplexy, Cranio-Encephalic MRI, Cephalodynia, Pituitary Adenoma 


\section{Introduction}

Pituitary apoplexy corresponds to a sudden onset hemorrhagic or ischemic rearrangement within a pituitary adenoma [1]. It is an endocrine as well as neurosurgical emergency involving the vital prognosis [2]. Pituitary apoplexy is a rare complication most often inaugural of a pituitary incidentaloma [3]. It presents diagnosis difficulties. Medical therapeutic and sometimes neurosurgical decisions must be taken early. The classic clinical picture combines sudden installation headaches, consciousness disorders, endocrine disorders and ophthalmologic manifestations in the form of decreased unilateral or bilateral visual acuity in relation to acute compression of chiasma and oculomotor paralysis.

We case we report is the one of a patient who abruptly presented headaches secondly followed by a left visual field defect. The cranio-encephalic MRI performed allowed the diagnosis of pituitary apoplexy.

\section{Observation}

A 57-years-old female patient called K.A was received in a Radiodiagnosis and Medical Imaging Department of our town for cranio-encephalic MRI. At the interrogation, she had no particular antecedents. There was also no obvious endocrine disorder. Clinical examination revealed diffuse headaches and an alteration of the consciousness consciousness to the type of obstruction. Visual acuity was normal right for $10 / 10^{\text {th }}$ and $4 / 10^{\text {th }}$ left. The fundus of the eye was normal on the right with a retina and a papilla without any particular abnormality; But on the left there was a papillary edema. The field of vision was normal to the right. On the left, there was a temporal hemianopia. Magnetic resonance imaging (MRI) revealed an intrasellar expansive process with suprasellar extension. This lesion was containing heterogeneous signal on all the sequences performed [Figure 1, Figure 2], alternating hemorrhagic stigmata in the central tumor zone [Figure 3] that made us suggest a having bled macroadenoma, compatible with pituitary apoplexy. The contours of this mass were relatively regular. The tumor had an important mass effect on the optic chiasm which was stretched and pushed back up and down. The lesion invaded the suprasellar and infrasellar [Figure 4]. After the injection of gadolinium, a heterogeneous contrast-enhanced lesion was observed [Figure 5]. The 3DTOF sequence (arteriography sequence) did not highlight any thrombosed macro aneurysm. The hormonal assessment performed was normal.

The management of this pituitary apoplexy associated with left ophtalmoplegia consisted after neurosurgical advice in an ophthalmological consultation at first. Vitamin B therapy was instituted. This ophthalmological medical treatment was sanctioned by the gradual recovery of visual acuity. A cranio-encephalic MRI performed two weeks later showed results superimposable to the previous one. This ophthalmological medical treatment has been associated with hormonotherapy. The outcome was the total recovery of visual acuity. 


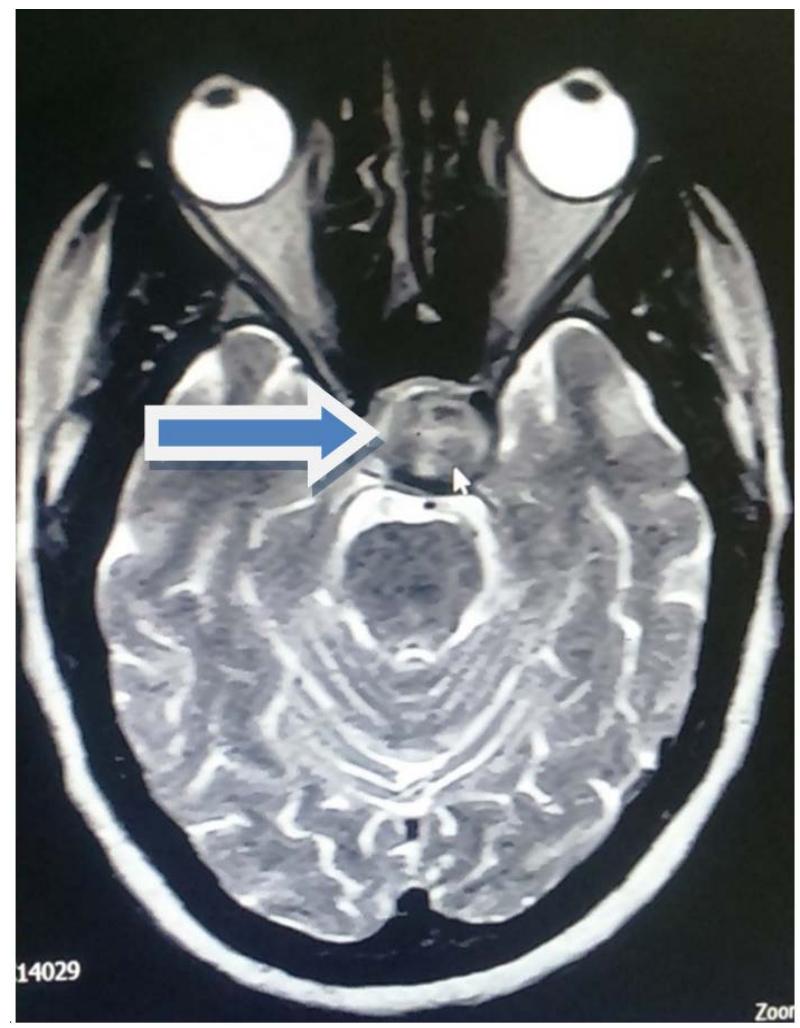

Figure 1. Axial EST2: Heterogeneous signal macroadenoma with suprasellar and lateral sellar extension (arrow head).

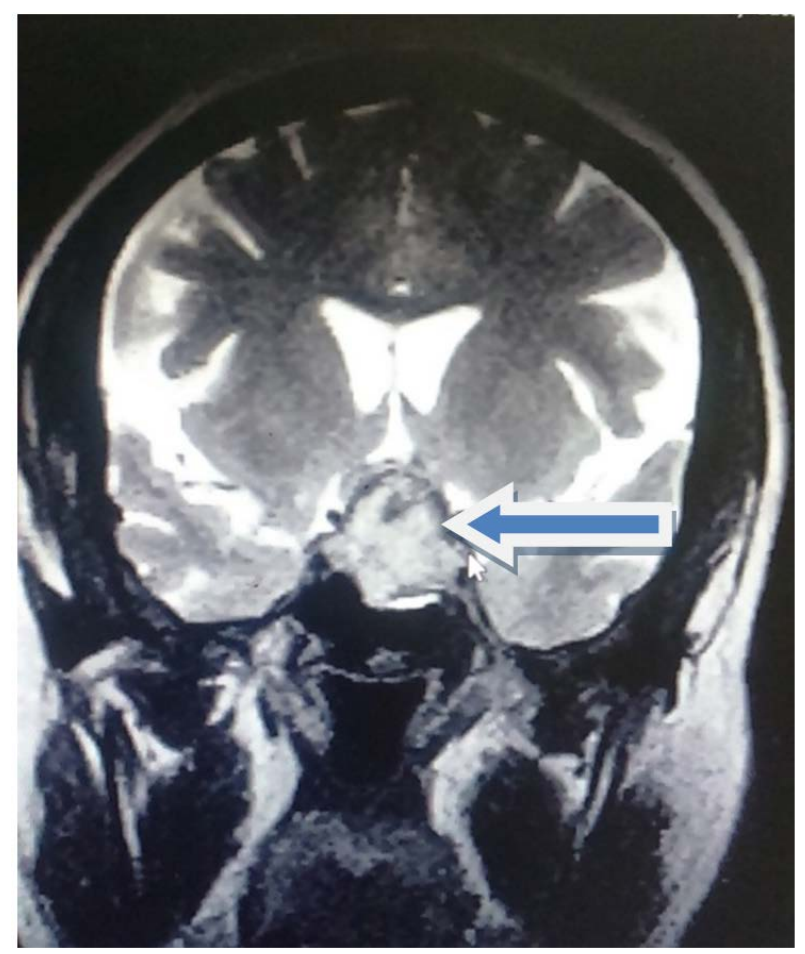

Figure 2. Coronale EST2: Heterogeneous macroadenoma compressing the optic chiasm with invasion of the left cavernous lodge (arrow head). 


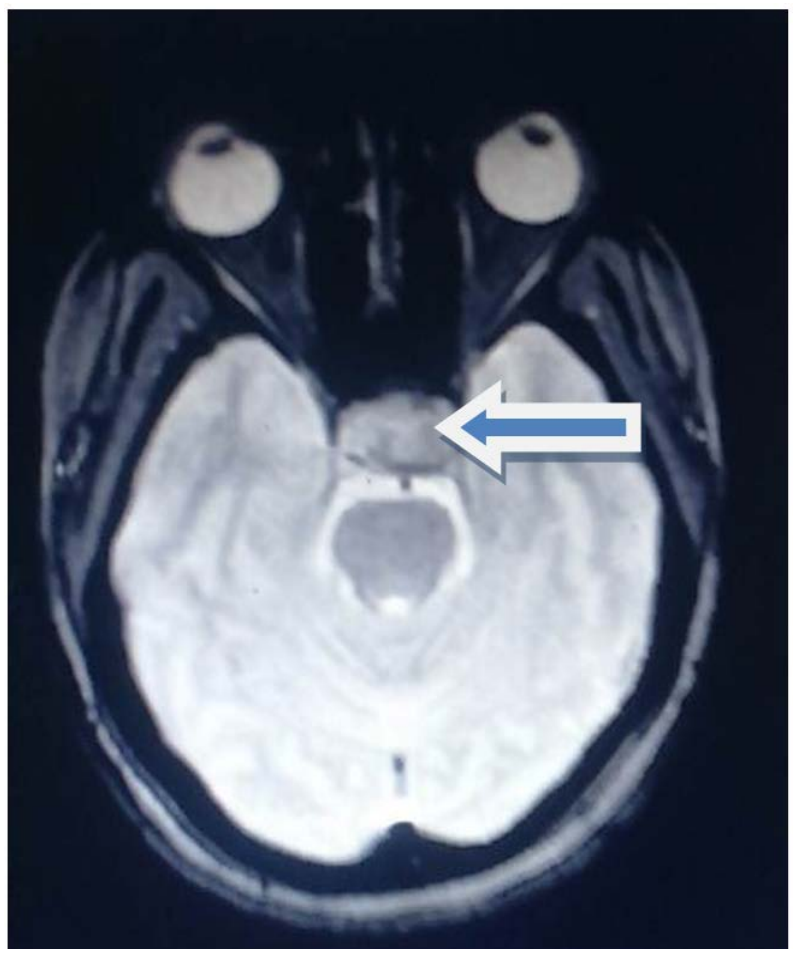

Figure 3. Axial gradient echo T2: Macroadenoma containing hemorrhagic stigmata (arrow head).

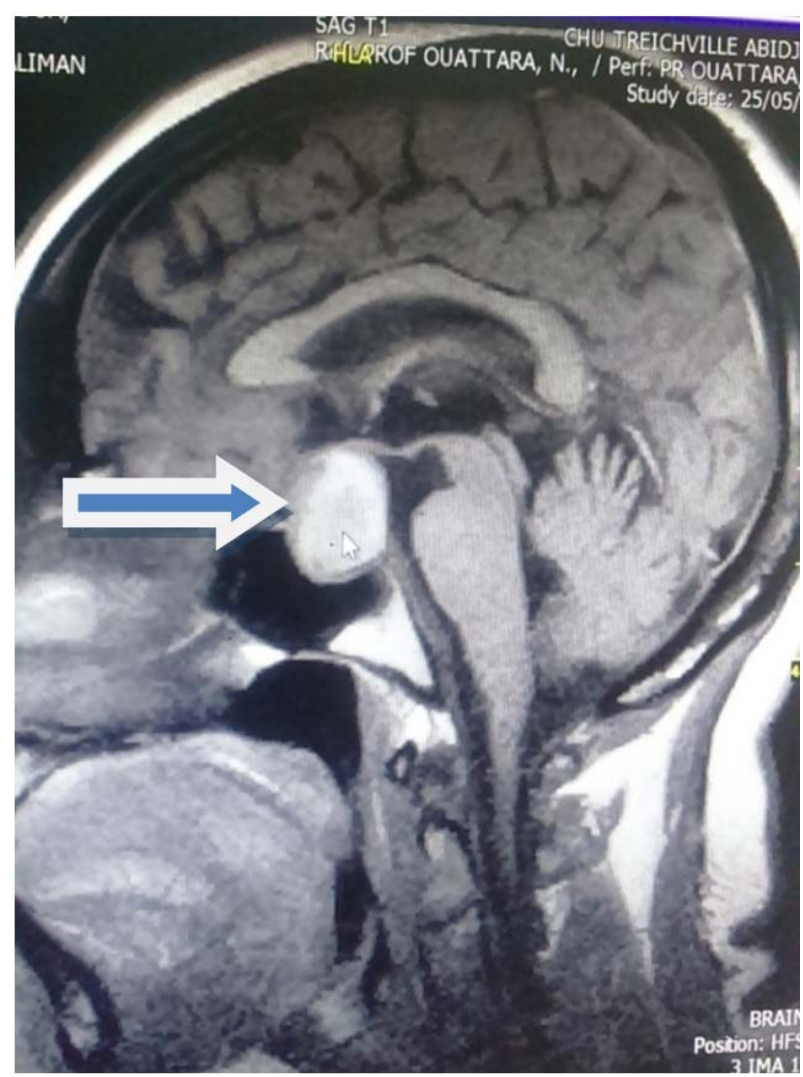

Figure 4. Sagittal EST1: Heterogeneous signal macroadenoma with suprasellar and infrasellar extension (arrow head). 


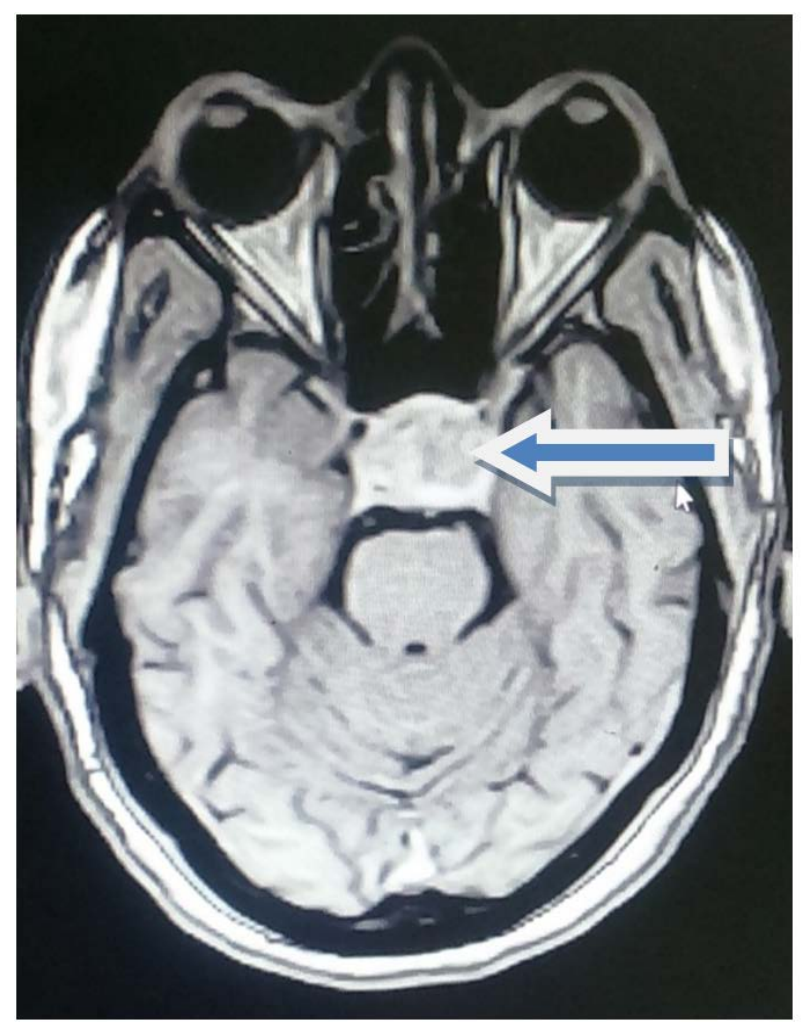

Figure 5. Axial ES T1 GADO: Heterogeneous contrast-enhanced of the Macroadenoma (arrow head).

\section{Discussion}

Pituitary apoplexy is a rare and unknown complication in patients with pituitary adenoma [Table 1] [4]. It affects both genders with an average age between 40 and 50 years old [5]. The age of our patient was close to authors description. It involves less than $4 \%$ of patients with pituitary adenoma. In most cases, patients do not know the existence of their adenoma. The acute complication being one of the circumstances of discovery of the adenoma. These are mostly acute accidents with dramatic consequences on both visual and endocrine function [3] [6].

Clinical manifestations of pituitary apoplexy are varied, with abrupt headaches, usually retro-orbital or frontal, and sometimes diffuse [7]. They are present in $76 \%$ of cases and can mimic the pain observed in meningeal irritations [8]. Anomalies of vision were found in $62 \%$ of cases [9] [10]. This decrease in visual acuity and alteration of the visual field are due to the expansion of the tumor with compression of the chiasma and/or optic nerves. The deterioration can range from simple bitemporal hemianopia to total blindness [11]. A diplopia with oculomotor disorder occurs in $40 \%$ of patients [12] [13]. The three pairs of oculomotor cranial nerves may be affected by compression or tumor invasion of the cavernous sinus. The third cranial pair is the most common [14]. The disorders of consciousness present in 17 to $38 \%$ of cases [15] going from simple somnolence to coma are related to the compression of the diencephalon. Endocrine disorders are very common with sudden anaphylactic insufficiency [8]. 
Table 1. Summary of previous large retrospective studies about pituitary apoplexy (PA) published in European journal of endocrinology.

\begin{tabular}{|c|c|c|c|c|}
\hline \multirow{2}{*}{ Study } & \multirow{2}{*}{$\begin{array}{l}\text { Number } \\
\text { Of } \\
\text { patients }\end{array}$} & \multicolumn{2}{|c|}{ Incidence of AP } & \multirow[b]{2}{*}{ Essential information } \\
\hline & & $\mathrm{n}$ & $\%$ & \\
\hline 1) & 560 & 51 & 9.1 & $\begin{array}{l}\text { AP is not correlated with sex, endocrine function or } \\
\text { histological type of adenoma, but with age. }\end{array}$ \\
\hline 2) & & 37 & & $\begin{array}{l}\text { In stable AP patients, surgical decompression should be } \\
\text { performed as early as possible, as delays beyond } 1 \text { week } \\
\text { may delay visual function recovery. }\end{array}$ \\
\hline 3) & 799 & 39 & 4.9 & $\begin{array}{l}\text { The authors suggest surgical treatment in all AP cases to } \\
\text { improve neurological and endocrine recovery. }\end{array}$ \\
\hline 4) & 125 & 16 & 12.8 & $\begin{array}{l}\text { In AP, surgical treatment was associated with a better } \\
\text { outcome than treatment with dexamethasone. }\end{array}$ \\
\hline 5) & 982 & 35 & 3.2 & $\begin{array}{l}\text { Hypertension can be an important predisposing factor } \\
\text { for BP. Trans-sphenoid surgery is safe and effective. It is } \\
\text { indicated if there are associated abnormalities of visual } \\
\text { acuity or field of vision. }\end{array}$ \\
\hline 6) & & 45 & & $\begin{array}{l}\text { Patients with classical AP and none or only mild and } \\
\text { non-progressive neuro-ophthalmic signs can be ma- } \\
\text { naged conservatively in the acute stage. }\end{array}$ \\
\hline 7$)^{a}$ & 721 & 27 & 3.7 & $\begin{array}{l}\text { Anterior pituitary function was more often conserved, } \\
\text { normalized or even improved after trans-sphenoidal } \\
\text { surgery compared to transcranial surgery in patients } \\
\text { with non-functional pituitary adenomas. }\end{array}$ \\
\hline 8) & & 62 & & $\begin{array}{l}\text { Emergency surgery is required in patients with decreased } \\
\text { consciousness, impaired vision, or sudden blindness. } \\
\text { Isolated cranial nerve palsies can be effectively managed } \\
\text { conservatively. }\end{array}$ \\
\hline 9$)^{a}$ & 192 & 41 & 21 & $\begin{array}{l}\text { AP occurs more frequently than is usually assumed. In } \\
\text { patients operated for a non-functional pituitary adeno- } \\
\text { ma, survival is independent of the onset of AP. }\end{array}$ \\
\hline 10) & 1540 & 24 & 1.6 & $\begin{array}{c}\text { AP is a rare event. Complete recovery is possible if the } \\
\text { diagnosis is made quickly and proper management in- } \\
\text { itiated on time. The surgical results are very satisfactory } \\
\text { in most cases. }\end{array}$ \\
\hline (11) & 262 & 25 & 9.5 & $\begin{array}{l}\text { Classic AP is a rare event. The incidence of subclinical } \\
\text { AP is higher than the standard AP. } \\
\text { Patients with classical AP have a higher mean age and } \\
\text { most patients are male ( } 68 \%) \text {. Visual improvement is } \\
\text { better in sub-clinical AP than in conventional AP. In } \\
\text { classical and subclinical AP, the anterior pituitary func- } \\
\text { tion is able to recover. }\end{array}$ \\
\hline
\end{tabular}

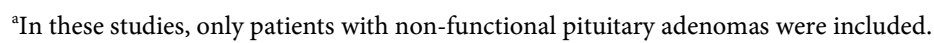

In the case we involved, the clinical manifestations were similar to those described by other authors [4] [Table 2], except endocrine and alertness disorders which were absent. These constituted factors of good prognosis.

CT scan and MRI can easily be used to confirm this diagnosis, but cranio-encephalic MRI is the best reference for the diagnosis of the pituitary ade- 
noma and the pituitary apoplexy complication [9]. MRI allows visualizing the tumor and assessing its extension. It also makes it possible to assess the hemorrhagic or ischemic rearrangement of the pituitary adenoma. Our observation we made described on the gradient spin echo sequences, hemorrhagic stigmata within the macroadenoma which exerted an important mass effect on the optic chiasm and the cavernous sinus.

The evolution of the clinical symptomatology depends on the delay of management. The treatment always involves substitutive hormonotherapy as well as taking into acount pituitary apoplexy predisposing factors [4] [Table 3]. The hormonotherapy is supplemented by surgical intervention which will consist in an excision of the necrosed adenoma by trans-sphenoidal approach [10]. Surgical intervention is urgently performed when there is a compression of the optic

Table 2. Symptoms associated with PA like published in European journal of endocrinology.

\begin{tabular}{|c|c|c|c|c|c|}
\hline \multirow[t]{2}{*}{ Symptoms } & \multicolumn{2}{|c|}{$\begin{array}{l}\text { With AP } \\
(n=42)\end{array}$} & \multicolumn{2}{|c|}{$\begin{array}{c}\text { Control } \\
\text { group } \\
(\mathrm{n}=84)\end{array}$} & \multirow[t]{2}{*}{${ }^{\text {aa }} \mathrm{P}$ value } \\
\hline & $\mathrm{n}$ & $\%$ & $\mathrm{n}$ & $\%$ & \\
\hline Ophthalmoplegia & 32 & 76 & 4 & 5 & $<0.001$ \\
\hline Deficiency of the visual field & 16 & 38 & 46 & 55 & 0.091 \\
\hline Chronic headaches & 5 & 12 & 20 & 24 & 0.156 \\
\hline Amenorrhea $^{\mathrm{b}}$ & 6 & 50 & 9 & 38 & 0.499 \\
\hline Galactorrhea $^{\mathrm{b}}$ & 2 & 17 & 4 & 17 & 1.00 \\
\hline Hypopituitarism & 19 & 45 & 40 & 48 & 0.851 \\
\hline
\end{tabular}

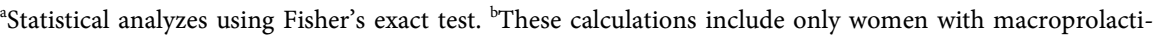
noma ( $\mathrm{n}=12$ or 24 , respectively.

Table 3. Pituitary apoplexy predisposing Factors published in European journal of endocrinology.

\begin{tabular}{|c|c|c|c|c|c|}
\hline \multirow[t]{2}{*}{ factors } & \multicolumn{2}{|c|}{$\begin{array}{l}\text { With AP } \\
(n=42)\end{array}$} & \multicolumn{2}{|c|}{$\begin{array}{l}\text { Control } \\
\text { group } \\
(n=84)\end{array}$} & \multirow[t]{2}{*}{${ }^{\text {ap }} \mathrm{P}$ value } \\
\hline & $\mathrm{n}$ & $\%$ & $\mathrm{n}$ & $\%$ & \\
\hline Thrombolytic therapy & 12 & 29 & 10 & 12 & 0.026 \\
\hline Diabetic sugar & 4 & 10 & 8 & 10 & 1.00 \\
\hline Hypertension & 9 & 21 & 19 & 23 & 1.00 \\
\hline Dopamine agonist & 0 & 0 & 11 & 13 & - \\
\hline estrogen & 2 & 1000 & 0 & & - \\
\hline$(\text { Deposit injection })^{\mathrm{b}}$ & 1 & 2 & 0 & 0 & - \\
\hline Bilateral adrenalectomy & 1 & 2 & 0 & 0 & - \\
\hline Heart surgery & 3 & 7 & 0 & 0 & - \\
\hline
\end{tabular}

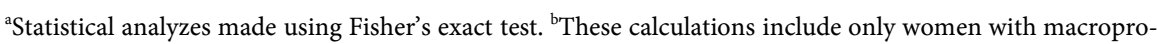
lactinoma ( $\mathrm{n}=12$ or 24 , respectively). 
chiasm by the adenoma associated with alertness disorders [11]. It is therefore important that the surgical treatment being performed in order to avoid a recurrence of pituitary apoplexy [12]. In our study, the patient received ophthalmological treatment followed by hormonotherapy and surgical excision of the adenoma. The outcome was favorable marked by a recovery of left visual field and a disappearance of headaches.

\section{Conclusion}

Pituitary apoplexy is an emergency diagnosis complication of pituitary adenoma. It involves functional and vital prognosis. CT scan or cranio-encephalic MRI confirms the diagnosis. The combination of hormonotherapy and excision of the tumor by trans-sphenoidal approach results in favorable sequences and recovery of the visual function.

\section{References}

[1] Lath, R. and Rajshekhar, V. (2001) Massive Cerebral Infarction as a Feature of Pituitary Apoplexy. Neurology India, 49, 191-193.

[2] Arafah, B.M., Taylor, H.C., Salazar, R., Saadi, H. and Selman, W.R. (1989) Apoplexy of a Pituitary Adenoma after Dynamic Testing with Gonadotropin-Releasing Hormone. The American Journal of Medicine, 87, 103-105. https://doi.org/10.1016/S0002-9343(89)80494-2

[3] Galland, F., Vantyghem, M.C., Cazabat, L., Boulin, A., Cotton, F., Bonneville, J.F., Jouanneau, E., Vidal-Trécan, G. and Chanson, P. (2015) Management of Non Functioning Pituitary Incidentaloma. Annales D’ Endocrinologie (Paris), 76, 191-200. https://doi.org/10.1016/j.ando.2015.04.004

[4] Möeller-Goede, D.L., Brändle, M., Landau, K., Bernays, R.L. and Schmid, C. (2011) Pituitary Apoplexy: Re-Evaluation of Risk Factors for Bleeding into Pituitary Adenomas and Impact on Outcome. European Journal of Endocrinology, 164, 37-43. https://doi.org/10.1530/EJE-10-0651

[5] Akutsu, H., Noguchi, S., Tsunoda, T., Sasaki, M. and Matsumura, A. (2004) Cerebral Infarction Following Pituitary Apoplexy-Case Report. Neurologia Medico-Chirurgica (Tokyo), 44, 479-483. https://doi.org/10.2176/nmc.44.479

[6] Sibal, L., Ball, S.G., Connolly, V., James, R.A., Kane, P., Kelly, W.F., et al. (2004) Pituitary Apoplexy: A Review of Clinical Presentation, Management and Outcome in 45 Cases. Pituitary, 7, 157-163. https://doi.org/10.1007/s11102-005-1050-3

[7] Biousse, V. and Makki, A. (2005) Pituitary Apoplexy. Revue Neurologique (Paris), 161, 587-589. https://doi.org/10.1016/S0035-3787(05)85095-7

[8] Yang, S., Lee, K., Lee, K., Lee, S. and Hong, Y. (2008) Pituitary Apoplexy Producing Internal Carotid Artery Compression: A Case Report. Journal of Korean Medical Science, 23, 1113-1117. https://doi.org/10.3346/jkms.2008.23.6.1113

[9] Jeon, B., Park, Y., Oh, H., Kim, Y. and Chun, B. (2007) Pituitary Apoplexy Complicated by Chemical Meningitis and Cerebral Infarction. Journal of Korean Medical Science, 22, 1085-1089. https://doi.org/10.3346/jkms.2007.22.6.1085

[10] Brougham, M., Heusner, A.P. and Adams, R.D. (1950) Acute Degenerative Changes in Adenomas of the Pituitary Body-With Special Reference to Pituitary Apoplexy. Journal of Neurosurgery, 7, 421-439. https://doi.org/10.3171/jns.1950.7.5.0421 
[11] Pozzati, E., Frank, G., Nasi, M. and Giuliani, G. (1987) Pituitary Apoplexy, Bilateral Carotid Vasospasm, and Cerebral Infarction in a 15-Year-Old Boy. Neurosurgery, 20, 56-59. https://doi.org/10.1227/00006123-198701000-00015

[12] McFadzean, R.M., Doyle, D., Rampling, R., Teasdale, E. and Teasdale, G. (1999) Pituitary Apoplexy and Its Effect on Vision. Neurosurgery, 9, 669-676.

[13] Bruce, B.B., Biousse, V. and Newman, N.J. (2007) Third Nerve Palsies. Seminars in Neurology, 27, 257-268. https://doi.org/10.1055/s-2007-979681

[14] Milazzo, S., Toussaint, P., Proust, F., Touzet, G. and Malthieu, D. (1996) Ophthalmologic Aspects of Pituitary Apoplexy. European Journal of Ophthalmology, 6, 69-73.

[15] Rolih, C.A. and Ober, K.P. (1993) Pituitary Apoplexy. Endocrinology Metabolism Clinics of North America, 22, 291-302. 